\title{
Assessment of right atrial and right ventricular size in children after percutaneous closure of secundum atrial septal defect with Amplatzer septal occluder
}

Beata Kucinska, Bożena Werner, Maria Wróblewska-Kałużewska

Department of Pediatric Cardiology and General Pediatrics, Medical University of Warsaw, Warsaw, Poland

Submitted: 20 September 2009

Accepted: 10 October 2009

Arch Med Sci 2010; 6, 4: 567-572

DOI: 10.5114/aoms.2010.14469

Copyright @ 2010 Termedia \& Banach

\section{Abstract}

Introduction: The aim of this study was to evaluate the right atrial (RA) and right ventricular (RV) size, and the speed of their normalization, in children after percutaneous closure of secundum atrial septal defect with the Amplatzer septal occluder.

Material and methods: The study group consisted of 42 children, aged 4.5 to 18.5 years. The following measurements (indexed to body surface area) were performed using 2D echocardiography: longitudinal, transverse axis and area of RA, RV inflow dimensions at one-third, and halfway between the tricuspid annulus and the apex (in the apical 4-chamber view), short axis and M-mode RV diastolic dimensions. All measurements were obtained $24 \mathrm{~h}$ and 1,3 and 12 months after the procedure, then annually over 4 years of follow-up, and compared with the values obtained from the control groups. Results: A significant decrease in all RA and RV values was observed after $24 \mathrm{~h}$. Right ventricular transverse dimension normalized after 1 month, the RA longitudinal axis and area and the RV inflow dimensions after 3 months, and the RA transverse axis and $\mathrm{M}$-mode RV diastolic dimension after 2 years, but the ratio of transverse to longitudinal RA axis remained significantly higher.

Conclusions: Right atrial and right ventricular measurements decrease rapidly during the first $24 \mathrm{~h}$, and most of them normalize within a 3-month period. M-mode RV diastolic dimension does not capture the real RV changes. Amplatzer septal occluder closure of ASD influences the RA geometry, which is reflected by the higher transverse to longitudinal RA axis ratio.

Key words: atrial septal defect, Amplatzer, children.

\section{Introduction}

Secundum atrial septal defect (ASD II) is one of the most common cardiac defects, accounting for approximately $6 \%$ to $10 \%$ of all congenital cardiac anomalies in children.

Marked progress in interventional cardiology has led to the development of a non-surgical method for ASD II treatment, and percutaneous closure of single ASDII has become the standard of treatment, possible in about $60-70 \%$ of patients depending on the defect location, size and patient's age [1-3]. The Amplatzer septal occluder (ASO) has been used since 1995. After multicentre clinical trials, the device was approved by the United States Food and Drug Administration (FDA) in 2002 for use in children and adults. For transcatheter closure using the Amplatzer septal occluder,

\author{
Corresponding author: \\ Beata Kucinska, PhD \\ Department of Pediatric \\ Cardiology and General \\ Pediatrics \\ Medical University \\ of Warsaw, Poland, \\ 24 Marszałkowska St. \\ 00-576 Warsaw, Poland \\ Phone/fax: +48 226298317 \\ E-mail: \\ beatakucinska@yahoo.com
}


additional criteria are that the ASD II diameter is not excessively large for currently available devices, and there should be a distance of $>5 \mathrm{~mm}$ from the margins of the defect to the coronary sinus, atrioventricular valves and right upper pulmonary vein $[4,5]$. The contraindications for percutaneous closure include too big defect or too small surrounding rims (except for the anterior rim toward the aorta). Symptomatic infants are usually treated surgically; however, the percutaneous approach has been performed in children with body weight less than $10 \mathrm{~kg}$. Patients who do not fulfil criteria for percutaneous closure are qualified for open heart
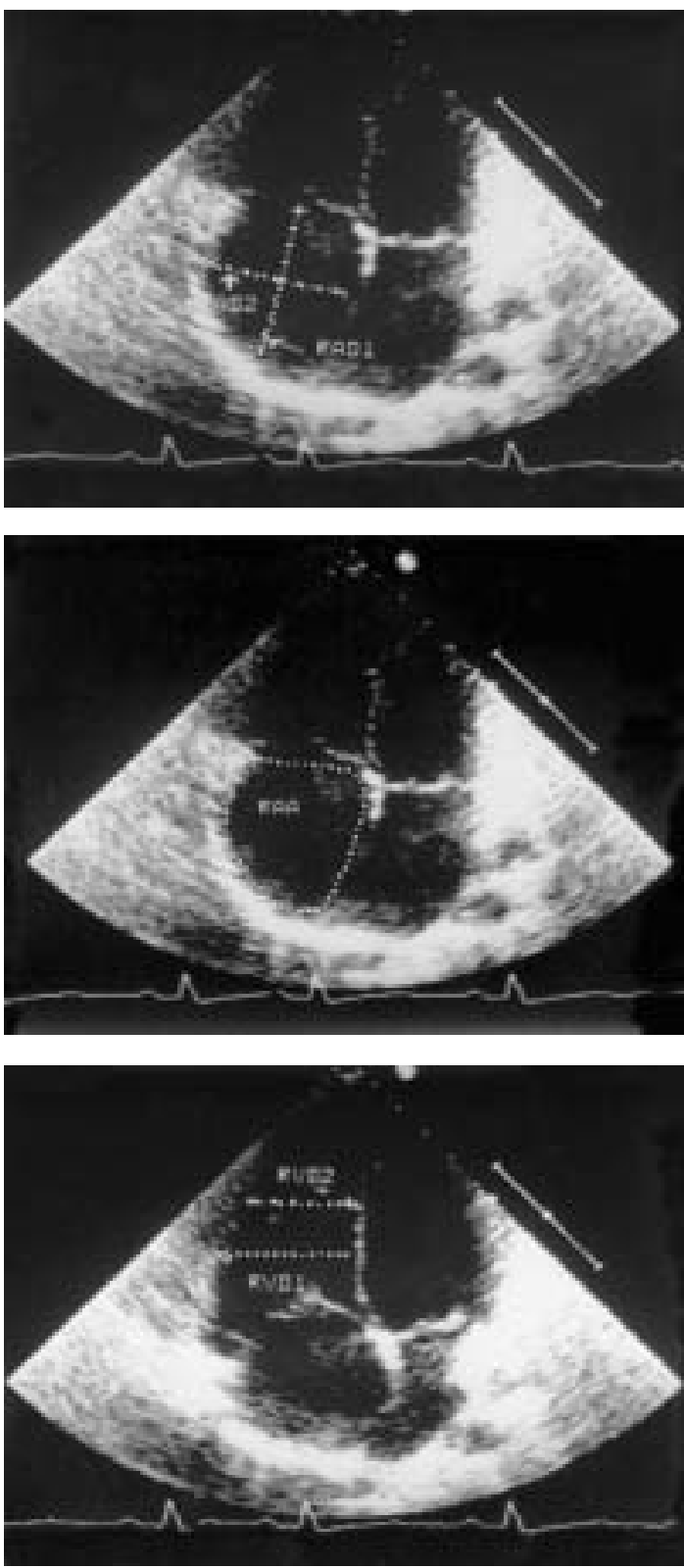

Figure 1. Echocardiographic measurements of right atrial $\left(R A D_{1}, R A D_{2}, R A A\right)$ and right ventricular dimensions $\left(\mathrm{RVD}_{1}, \mathrm{RVD}_{2}\right)$

$R A D$ - right atrial dimension, $R A A$ - right atrial area, $R V D$ - right ventricular dimension surgery, which is performed with good results in patients from the infancy period to late adulthood, although it is associated with morbidity, discomfort and a thoracotomy scar $[6,7]$.

Right ventricular and right atrial volume overload are well known consequences of unclosed ASD II. Persistent shunt, resulting in right atrial dilation, may lead to symptomatic cardiac arrhythmias [1].

The aim of this study was to evaluate the right atrial (RA) and right ventricular (RV) size and the speed of their normalization in children after percutaneous closure of secundum atrial septal defect with the Amplatzer septal occluder.

\section{Material and methods}

The study group consisted of 42 children treated with percutaneous closure of ASD II. The children ranged in age from 4.5 years to 18.5 years (mean: 11.7 years), and ranged in weight from $16 \mathrm{~kg}$ to $97.5 \mathrm{~kg}$ (mean: $42.7 \mathrm{~kg}$ ). The patients' heights ranged from $106 \mathrm{~cm}$ to $176 \mathrm{~cm}$ (mean: $145.8 \mathrm{~cm}$ ), and their body surface area (BSA) ranged from $0.69 \mathrm{~m}^{2}$ to $1.87 \mathrm{~m}^{2}$ (mean $1.3 \mathrm{~m}^{2}$ ).

Transthoracic, two-dimensional echocardiography (Acuson Aspen system with 2.5-4 MHz probes) was used for ASD II diagnosis, preliminary qualification for the procedure, and RA and RV measurements. Echocardiography was performed by the same investigator in all patients. Each measurement was undertaken 3 times, and the mean values were taken for analysis.

In the apical 4-chamber view, the following RA parameters were determined $[8,9]$ :

1) $R A D_{1}$ - the longitudinal RA axis measured from the level of the tricuspid valve annulus to the opposite upper RA wall;

2) $R A D_{2}$ - the transverse RA axis measured perpendicular to the longitudinal axis in its midlength;

3) RAA - the RA surface area planimetrically determined (Figure 1).

Each measurement was obtained at end-systole of the ventricles, as recommended by Weyman [9], and averaged from three consecutive cardiac cycles. The ratio of transverse to longitudinal axis $\left(\mathrm{RAD}_{2} / \mathrm{RAD}_{1}\right)$ was also calculated.

Because of the non-geometric shape of the RV the evaluation of RV size was made based on the measurements obtained from two-dimensional echocardiography, at end diastole, as recommended by Foale et. al., [10] and M-mode examination:

1) $R V D_{1}$ - measurement of the $R V$ inflow dimension assessed in the apical 4-chamber view at one-third the distance from the tricuspid annulus to the apex;

2) $R V D_{2}$ - measurement of the median RV dimension assessed in the apical 4-chamber view halfway between the tricuspid annulus and the apex (Figure 1); 
3) $R V D_{3}$ - measurement of the RV transverse dimension assessed in the parasternal short axis view at the level of the mitral valve measured from the free wall of the right ventricle to the interventricular septum;

4) $R V D_{4}$ - measurement of the RV end-diastolic dimension assessed in M-mode echocardiography from the parasternal long axis view at the level of the mitral valve chordae tendineae.

The follow-up TTE examinations were carried out at 24 h, 1, 3 and 12 months, and then annually for 4 years after the procedure. The control groups consisted of healthy children matched for age, body weight, height and body surface area with the study group.

The results of measurements in the study group obtained before the procedure and $24 \mathrm{~h}$, 1 month, and 3 months after the procedure were compared with those of control K. The data obtained from the study group at 1, 2, 3, and 4 years after the procedure were compared with controls, K-1, K-2, K-3, K-4, respectively. For characteristics of the control groups see Table I.

One patient was excluded from statistical analysis due to concomitant significant valvular pulmonary artery stenosis, and another patient was excluded for non-compliance reasons.

Statistical analysis was performed with the statistical software package SPSS/PC+. Following confirmation with the Shapiro-Wilk test of normal distribution of continuous variables, the statistics of location and dispersion were described, including mean values, standard deviation and (in the case of significant dispersion) standard error of the mean (relative losses - differences in measurements in initial and remote phases).

Differences in the mean of more than two consecutive measurements were tested with repetitive analysis of variance, using the previous result as a contrast. For paired variables in the control groups and the study group (age, body weight, height, body surface area and gender), Student's $t$-test for related groups was used. A value of $p<0.05$ was considered to be statistically significant. All tests were performed two-tailed.

\section{Results}

Single ASO were used in all patients, with diameters ranging from $11 \mathrm{~mm}$ to $30 \mathrm{~mm}$ and a mean diameter of $17.5 \pm 4.5 \mathrm{~mm}$.

Complete closure was achieved in 38 children immediately after the procedure and in 40 patients after 1 year. There were no major complications during the procedure and follow-up. In 2 patients technical problems occurred: in 1 the Eustachian valve was entrapped on the delivery system, and in another patient the device was unstable and was repositioned. During follow-up 1 teenager developed symptomatic atrial fibrillation 3 weeks after the procedure.

\section{Indexed right atrial measurements}

Table II presents the mean values of RA indexed measurements before the procedure and after percutaneous closure of the defect and the results of statistical analysis.

Before the procedure, all RA measurements were significantly higher in the study group than in the control group K $(p<0.0001)$. Twenty-four $h$ following defect closure, the mean values of all assessed parameters decreased significantly as compared to the pre-procedure values; at 1 month, further significant reduction was observed only for RAA/BSA. The values of $R A D_{1} / B S A$ and $R A D_{2} / B S A$ remained significantly higher than in the control group $\mathrm{K}$ at $24 \mathrm{~h}$ and 1 month after ASD closure.

Table I. Control groups' characteristics with the values of right atrial and right ventricular measurements

\begin{tabular}{|c|c|c|c|c|c|}
\hline Parameter & $\mathrm{K}(n=40)$ & $\mathrm{K}-1(n=40)$ & $\mathrm{K}-2(n=13)$ & $\mathrm{K}-3(n=8)$ & $\mathrm{K}-4(n=13)$ \\
\hline Age [years] & $11.2 \pm 4.2(\mathrm{~ns})$ & $12.5 \pm 3.6(n s)$ & $12.2 \pm 4.4$ (ns) & $12.7 \pm 4.2(\mathrm{~ns})$ & $14.0 \pm 4.2$ (ns) \\
\hline Body weight [kg] & $41.9 \pm 16.4$ (ns) & $46.0 \pm 13.6$ (ns) & $45.4 \pm 19.6$ (ns) & $44.3 \pm 14.1$ (ns) & $50.2 \pm 14.5$ (ns) \\
\hline Height $[\mathrm{cm}]$ & $147 \pm 23$ (ns) & $154 \pm 16$ (ns) & $153 \pm 22$ (ns) & $153 \pm 18$ (ns) & $158 \pm 16$ (ns) \\
\hline $\mathrm{BSA}\left[\mathrm{m}^{2}\right]$ & $1.30 \pm 0.36$ (ns) & $1.40 \pm 0.28$ (ns) & $1.38 \pm 0.40$ (ns) & $1.37 \pm 0.30$ (ns) & $1.48 \pm 0.29$ (ns) \\
\hline $\mathrm{RAD}_{1} / \mathrm{BSA}\left[\mathrm{mm} / \mathrm{m}^{2}\right]$ & $28.7 \pm 7.0$ & $27.7 \pm 5.5$ & $27.5 \pm 5.1$ & $27.5 \pm 3.8$ & $26.7 \pm 4.6$ \\
\hline $\mathrm{RAD}_{2} / \mathrm{BSA}\left[\mathrm{mm} / \mathrm{m}^{2}\right]$ & $25.1 \pm 6.1$ & $24.0 \pm 5.3$ & $24.2 \pm 5.3$ & $23.3 \pm 3.7$ & $23.0 \pm 4.4$ \\
\hline $\mathrm{RAA} / \mathrm{BSA}\left[\mathrm{cm}^{2} / \mathrm{m}^{2}\right]$ & $8.6 \pm 1.6$ & $8.5 \pm 1.5$ & $8.0 \pm 1.1$ & $8.0 \pm 1.5$ & $8.5 \pm 1.5$ \\
\hline $\mathrm{RVD}_{1} / \mathrm{BSA}\left[\mathrm{mm} / \mathrm{m}^{2}\right]$ & $27.7 \pm 6.1$ & $26.7 \pm 5.4$ & $26.4 \pm 4.8$ & $26.3 \pm 3.1$ & $25.7 \pm 4.2$ \\
\hline $\mathrm{RVD}_{2} / \mathrm{BSA}\left[\mathrm{mm} / \mathrm{m}^{2}\right]$ & $22.9 \pm 5.1$ & $21.5 \pm 4.6$ & $21.2 \pm 4.1$ & $21.3 \pm 2.8$ & $20.8 \pm 4.1$ \\
\hline $\mathrm{RVD}_{3} / \mathrm{BSA}\left[\mathrm{mm} / \mathrm{m}^{2}\right]$ & $19.3 \pm 5.1$ & $17.7 \pm 4.2$ & $18.1 \pm 4.1$ & $17.8 \pm 2.6$ & $17.0 \pm 3.7$ \\
\hline $\mathrm{RVD}_{4} / \mathrm{BSA}\left[\mathrm{mm} / \mathrm{m}^{2}\right]$ & $14.4 \pm 3.5$ & $13.6 \pm 2.9$ & $13.8 \pm 2.6$ & $13.1 \pm 2.0$ & $12.9 \pm 2.2$ \\
\hline
\end{tabular}

$R A D$ - right atrial dimension, $R A A$ - right atrial area, $R V D$ - right ventricular dimension, $B S A$ - body surface area, $K$ - control group, $n$-number of children, $n s$ - differences not significant $(p>0.05)$ compared with study group 
At 3 months, further significant reduction occurred for $\mathrm{RAD}_{1} / \mathrm{BSA}$ and RAA/BSA mean values but not for $R A D_{2} / B S A$, which significantly decreased after 1 year but still remained higher compared to $\mathrm{K}-1$ controls.

Mean values of indexed RA measurements after 2, 3 and 4 years did not differ significantly between each time point or as compared to respective control groups $(p>0.05)$.

\section{Right atrial transverse $\left(R A D_{2}\right)$ to longitudinal $\left(R A D_{1}\right)$ axis ratio}

Mean values of the $R A D_{2} / R A D_{1}$ ratio determined before and after the procedure, in both the study group and the control group, are presented in Table III. There were no differences in the mean $R A D_{2} / R A D_{1}$ values measured in the study group before and after the procedure. Following defect closure in children these values remained higher than in controls. This difference was statistically significant $(p<0.05)$ for all time points, except at 2 years following the procedure when it almost reached significance $(p=0.07)$

\section{Indexed right ventricular measurements}

The mean values of indexed RV measurements obtained before and after percutaneous closure of the defect and the statistical interpretation of the results are summarized in Table IV. Before the procedure all RV indexed measurements in the study group were significantly higher than in the control K groups.

Twenty-four $\mathrm{h}$ following defect closure, the mean values of all RV indexed parameters decreased significantly as compared to pre-procedure values, but $\mathrm{RVD}_{1} / \mathrm{BSA}, \mathrm{RVD}_{2} / \mathrm{BSA}$ and $\mathrm{RVD} \mathrm{D}_{4} / \mathrm{BSA}$ remained significantly higher than controls. No significant difference was demonstrated for $\mathrm{RVD}_{3} / \mathrm{BSA}$. Further significant reduction of all assessed RV parameters was also observed at 1 month, 3 months and 1 year following the procedure. Values of $\mathrm{RVD}_{4} / \mathrm{BSA}$ measured in the study group after 1 month, 3 months and 1 year of follow-up still remained larger than the values measured in the control group. The mean values of all RV measurements after 2, 3 and 4 years did not differ between each time point or as compared to respective control groups $(p>0.05)$.

Table II. Mean values of right atrial measurements before and after secundum atrial septal defect closure with results of statistical analysis

\begin{tabular}{|c|c|c|c|c|c|c|c|c|}
\hline \multirow{2}{*}{$\begin{array}{l}\mathrm{RA} \\
\text { measurements }\end{array}$} & \multirow{2}{*}{$\begin{array}{c}\text { ASD II } \\
(n=40)\end{array}$} & \multicolumn{7}{|c|}{ Time after ASD II closure } \\
\hline & & $\begin{array}{c}24 \mathrm{~h} \\
(n=40)\end{array}$ & $\begin{array}{l}1 \text { month } \\
(n=40)\end{array}$ & $\begin{array}{c}3 \text { months } \\
(n=40)\end{array}$ & $\begin{array}{c}1 \text { year } \\
(n=40)\end{array}$ & $\begin{array}{l}2 \text { years } \\
(n=13)\end{array}$ & $\begin{array}{l}3 \text { years } \\
(n=8)\end{array}$ & $\begin{array}{l}4 \text { years } \\
(n=13)\end{array}$ \\
\hline \multirow{2}{*}{$\begin{array}{l}\mathrm{RAD}_{1} / \mathrm{BSA} \\
{\left[\mathrm{mm} / \mathrm{m}^{2}\right]}\end{array}$} & $32.7 \pm 7.6^{*}$ & $30.6 \pm 7.0^{*}$ & $30.3 \pm 6.6^{*}$ & $29.0 \pm 6.5$ & $28.8 \pm 5.9$ & $28.9 \pm 5.4$ & $27.4 \pm 3.1$ & $26.6 \pm 2.9$ \\
\hline & & $p_{1}<0.0001$ & ns & $p_{3}<0.0001$ & ns & ns & ns & ns \\
\hline \multirow{2}{*}{$\begin{array}{l}\mathrm{RAD}_{2} / \mathrm{BSA} \\
{\left[\mathrm{mm} / \mathrm{m}^{2}\right]}\end{array}$} & $29.5 \pm 7.6^{*}$ & $27.8 \pm 7.1^{\star}$ & $27.4 \pm 7.1^{*}$ & $27.0 \pm 6.8^{\star}$ & $26.2 \pm 6.0^{*}$ & $26.3 \pm 5.7$ & $24.8 \pm 3.7$ & $24.5 \pm 3.1$ \\
\hline & & $p_{1}<0.0001$ & ns & ns & $p_{4}<0.05$ & ns & ns & ns \\
\hline \multirow{2}{*}{$\begin{array}{l}\mathrm{RAA} / \mathrm{BSA} \\
{\left[\mathrm{cm} / \mathrm{m}^{2}\right]}\end{array}$} & $10.2 \pm 1.9^{*}$ & $9.2 \pm 1.9$ & $9.0 \pm 1.7$ & $8.7 \pm 1.7$ & $8.7 \pm 1.5$ & $8.5 \pm 1.4$ & $8.2 \pm 1.0$ & $8.9 \pm 1.3$ \\
\hline & & $p_{1}<0.0001$ & $p_{2}<0.05$ & $p_{3}<0.05$ & ns & ns & ns & ns \\
\hline
\end{tabular}

$A S D$ II - secundum atrial septal defect, $R A$ - right atrium, $R A D$ - right atrial dimension, $R A A$ - right atrial area, BSA - body surface area, $n$-number of children, * difference statistically significant compared with control group, $p<0.05, p_{1}$ - before the procedure vs. $24 \mathrm{~h}$ after the procedure, $p_{2}-24 \mathrm{~h}$ vs. 1 month following defect closure, $p_{3}-1$ month vs. 3 months following defect closure, $p_{4}-3$ months vs. 1 year following defect closure, $n s$ - differences not significant, $p>0.05$

Table III. Right atrial transverse $\left(R A D_{2}\right)$ to longitudinal axis $\left(R A D_{1}\right)$ ratio in children before and after secundum atrial septal defect closure and in control groups

\begin{tabular}{|lcccccccc|}
\hline & \multicolumn{7}{c|}{ Follow-up } \\
\cline { 2 - 9 } & ASD II & & \multicolumn{7}{c|}{ After ASD II closure } \\
\cline { 2 - 10 } & & $24 \mathrm{~h}$ & 1 month & 3 months & 1 year & 2 years & 3 years & 4 years \\
\hline Study group & $0.9 \pm 0.07$ & $0.91 \pm 0.07$ & $0.9 \pm 0.07$ & $0.93 \pm 0.06$ & $0.91 \pm 0.07$ & $0.91 \pm 0.06$ & $0.91 \pm 0.06$ & $0.92 \pm 0.04$ \\
\hline Control group & $0.87 \pm 0.06$ & $0.87 \pm 0.06$ & $0.87 \pm 0.06$ & $0.87 \pm 0.06$ & $0.87 \pm 0.06$ & $0.88 \pm 0.06$ & $0.85 \pm 0.08$ & $0.86 \pm 0.09$ \\
\hline Value of $p$ & $<0.05$ & $<0.05$ & $<0.05$ & $<0.05$ & $<0.05$ & $n$ & $<0.05$ & $<0.05$ \\
\hline
\end{tabular}

$A S D$ II - secundum atrial septal defect, RAD - right atrial dimension, ns - differences not significant 
Table IV. Mean values of right ventricular measurements before and after secundum atrial septal defect closure with results of statistical analysis

\begin{tabular}{|c|c|c|c|c|c|c|c|c|}
\hline \multirow{2}{*}{$\begin{array}{l}\text { RA } \\
\text { measurements }\end{array}$} & \multirow{2}{*}{$\begin{array}{c}\text { ASD II } \\
(n=40)\end{array}$} & \multicolumn{7}{|c|}{ Time after ASD II closure } \\
\hline & & $\begin{array}{c}24 \mathrm{~h} \\
(n=40)\end{array}$ & $\begin{array}{l}1 \text { month } \\
(n=40)\end{array}$ & $\begin{array}{c}3 \text { months } \\
(n=40)\end{array}$ & $\begin{array}{c}1 \text { year } \\
(n=40)\end{array}$ & $\begin{array}{l}2 \text { years } \\
(n=13)\end{array}$ & $\begin{array}{l}3 \text { years } \\
(n=8)\end{array}$ & $\begin{array}{l}4 \text { years } \\
(n=13)\end{array}$ \\
\hline \multirow{2}{*}{$\begin{array}{l}\mathrm{RVD}_{1} / \mathrm{BSA} \\
{\left[\mathrm{mm} / \mathrm{m}^{2}\right]}\end{array}$} & $32.1 \pm 8.1^{*}$ & $30.1 \pm 7.3^{*}$ & $29.1 \pm 7.2$ & $27.9 \pm 7.2$ & $26.6 \pm 5.6$ & $27.9 \pm 6.0$ & $26.3 \pm 3.7$ & $25.6 \pm 3.1$ \\
\hline & & $p_{1}<0.0001$ & $p_{2}<0.0001$ & $p_{3}<0.0001$ & $p_{4}<0.01$ & ns & ns & ns \\
\hline \multirow{2}{*}{$\begin{array}{l}\mathrm{RVD}_{2} / \mathrm{BSA} \\
{\left[\mathrm{mm} / \mathrm{m}^{2}\right]}\end{array}$} & $26.1 \pm 6.7^{*}$ & $24.6 \pm 6.3^{*}$ & $23.9 \pm 5.8$ & $22.8 \pm 5.8$ & $21.0 \pm 4.7$ & $22.4 \pm 4.6$ & $21.0 \pm 3.1$ & $20.6 \pm 2.7$ \\
\hline & & $p_{1}<0.0001$ & $p_{2}<0.01$ & $p_{3}<0.0001$ & $p_{4}<0.05$ & ns & ns & ns \\
\hline \multirow{2}{*}{$\begin{array}{l}\mathrm{RVD}_{3} / \mathrm{BSA} \\
{\left[\mathrm{mm} / \mathrm{m}^{2}\right]}\end{array}$} & $22.0 \pm 4.7^{*}$ & $20.4 \pm 5.1$ & $19.4 \pm 4.6$ & $18.9 \pm 4.7$ & $17.7 \pm 3.6$ & $17.5 \pm 4.0$ & $17.0 \pm 3.1$ & $16.1 \pm 2.2$ \\
\hline & & $p_{1}<0.0001$ & $p_{2}<0.0001$ & $p_{3}<0.05$ & $p_{4}<0.001$ & ns & ns & ns \\
\hline \multirow{2}{*}{$\begin{array}{l}\mathrm{RVD}_{4} / \mathrm{BSA} \\
{\left[\mathrm{mm} / \mathrm{m}^{2}\right]}\end{array}$} & $19.5 \pm 4.7^{*}$ & $17.9 \pm 4.5^{\star}$ & $16.5 \pm 3.9^{\star}$ & $15.5 \pm 3.3^{\star}$ & $14.6 \pm 3.3^{*}$ & $13.8 \pm 2.6$ & $13.1 \pm 2.0$ & $12.9 \pm 2.2$ \\
\hline & & $p_{1}<0.0001$ & $p_{2}<0.0001$ & $p_{3}<0.0001$ & $p_{4}<0.01$ & ns & ns & ns \\
\hline
\end{tabular}

$A S D I I$ - secundum atrial septal defect, $R V$ - right ventricle, RVD - right ventricular dimension, $B S A$ - body surface area, $n$ - number of children, *difference statistically significant compared with control group, $p<0.05, p_{1}$ - before the procedure vs. $24 \mathrm{~h}$ after the procedure, $p_{2}-24 \mathrm{~h}$ vs. 1 month following defect closure, $p_{3}-1$ month vs. 3 months following defect closure, $p_{4}-3$ months vs. 1 year following defect closure, $n s$ - differences not significant, $p>0.05$

\section{Discussion}

In the study group, complete closure of the defect was observed in $90 \%$ of the children immediately after the procedure and in $95 \%$ of the children after 1 year. This finding was similar to published results $[6,11]$.

Technical problems which occurred in our patients had no impact on the final result of treatment and were reported previously [12]. Atrial fibrillation occurs frequently in adult patients following surgical closure of ASD II, as well as after other cardiosurgical procedures $[13,14]$. Other arrhythmias detected in 24-h ECG Holter monitoring could also occur after percutaneous closure using the Amplatzer septal occluder [15].

Changes in indexed RA measurements demonstrated a significant decrease in the longitudinal and transverse axis during the first $24 \mathrm{~h}$ after the procedure. The longitudinal axis as well as the right atrial surface area reached the mean value observed in controls after 3 months, whereas the transverse axis decreased more slowly and reached the control levels at 2 years after the procedure.

The results of a study by Kort et al. [16], performed on a group of 38 patients with ages ranging from 1 year to 69 years, are close to those obtained in our study in terms of the parameter values obtained $24 \mathrm{~h}$ post-procedure. The cited authors reported a marked decrease of indexed RA surface area during this time; however, the indexed RA surface area did not normalize during the subsequent 2 years of follow-up, while in our study it normalized after 3 months of follow-up. According to these authors, the decrease in the RA surface area was inversely related to the pre-closure age of the patient. The persistence of an increased RA surface area could be attributed to a relatively high proportion of older patients with ASD II, in whom normalization of RA surface area is slower.

Our study demonstrated that the RA transverse axis decreased more slowly than the longitudinal axis, which may reflect the change in RA geometry caused by ASO of ASD. The argument for this observation is the persistence of the increased ratio of $R A D_{2} / R A D_{1}$ (from 0.90 to 0.93 ) in patients during the 4 years of follow-up compared to healthy children (from 0.85 to 0.88 ). It is possible that the ASO may influence RA geometry by stiffening the interatrial septum, and this change may be reflected by a persistent increase in transverse RA axis. The role of a possible high geometric profile of the ASO was reported by Vogel et al. [17] based on their observations after ASD closure in children younger than 2 years of age.

In the studied children, all indexed RV measurements significantly decreased during the first $24 \mathrm{~h}$ after defect closure. During further followup all the parameters of RV assessed in the twodimensional study reached control levels during the

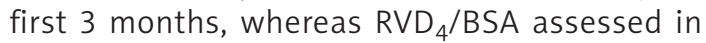
$M$-mode examination did not normalize until 2 years after defect closure. The results obtained by Eerola at al. [18] also show persistence of increased right ventricular $\mathrm{M}$-mode dimension more than 1 year but the haemodynamic improvement is still faster in children treated percutaneously than surgically.

Kort et al. [16] reported normalization of indexed $R V$ volume (RV volume/BSA) in children 2 years after ASD II closure with the ASO. It seems that due to the complexity of the RV geometry, in our opinion, the 
M-mode dimension alone does not capture the real ongoing changes in RV size after percutaneous closure of ASD and adding two-dimensional measurements could better reflect the ongoing changes. Also the use of three-dimensional echocardiography could be beneficial not only for assessment of RA but also for assessment of RV geometry $[18,19]$.

Our study had some limitations. The research group was heterogeneous, with patients' age ranging from 4.5 years to 18.5 years. The safety and efficacy of the procedure were not assessed in small children, because we qualified for percutaneous closure children with body weight higher than $15 \mathrm{~kg}$.

In conclusions, the right atrial and right ventricular measurements decrease rapidly during the first $24 \mathrm{~h}$, and most of them normalize within a 3-month period. M-mode RV diastolic dimension does not capture the real RV changes. Amplatzer septal occluder closure of ASD influences the RA geometry, which is reflected by the higher transverse to longitudinal RA axis ratio.

\section{References}

1. McMahon CJ, Feltes TF, Fraley JK, et al. Natural history of growth of secundum atrial septal defects and implications for transcatheter closure. Heart 2002; 87: 256-9.

2. King TD, Thompson SL, Steiner C, Mills NL. Secundum atrial septal defect - nonoperative closure during cardiac catheterization. JAMA 1976; 235: 2506-9.

3. Mills NL, King TD. Non operative closure of left to right shunts. J Thorac Cardiovasc Surg 1976; 72: 371-8.

4. Bialkowski J, Kusa J, Szkutnik M, et al. Percutaneous catheter closure of atrial septal defect. Short-term and mid-term results. Rev Esp Cardiol 2003; 56: 383-8.

5. Durongpisitkul K, Soongswang J, Laohaprasitiporn D, et al. Comparison of atrial septal defect closure using Amplatzer septal occluder with surgery. Pediatr Cardiol 2002; 23: 36-40.

6. Butera G, de Rosa G, Chessa M, et al. Transcatheter closure of atrial septal defect in young children, results and follow-up. J Am Coll Cardiol 2003; 42: 241-5.

7. Ugurlucan M, Yerebakan C, Al-Salem JA, et al. 79 yearsold patient with secundum type atrial septal defect. Arch Med Sci 2008; 4: 468-70.

8. Bommer W, Weinert L, Neumann A, Neef J, Mason DT, DeMaria A. Determination of right atrial and right ventricular size by two-dimensional echocardiography. Circulation 1979; 60: 91-100.

9. Rydlewska-Sadowska W (ed.). Echokardiografia kliniczna [Polish]. Wyd. Biblioteka Instytutu Kardiologii, Warszawa 1991.

10. Foale R, Nihoyannopoulos P, McKenna W, et al. Echocardio-graphic measurement of the normal adult right ventricle. Br Heart J 1986; 56: 33-44.

11. Omeish A, Hijazi ZM. Transcatheter closure of atrial septal defects in children and adults using the Amplatzer septal occluder. J Interv Cardiol 2001; 14: 37-44

12. Tarnowska A, Werner B, Godlewski K. Trudności w przeznaczyniowym zamykaniu ubytku w przegrodzie międzyprzedsionkowej - przetrwała zastawka Eustachiusza [Polish]. Kardiol Pol 2003; 59: 258-60.

13. Piechowiak $M$, Banach $M$, Ruta J, et al. Risk factors of atrial fibrillation in adult patients in long-term observation following surgical closure of atrial septal defect type II. Thorac Cardiovasc Surg 2006; 54: 259-63.

14. Banach M, Misztal M, Goch A, Rysz J, Goch JH. Predictors of atrial fibrillation in patients following isolated surgical revascularization. A metaanalysis of 9 studies with 28786 patients. Arch Med Sci 2007; 3: 229-39.

15. Kucinska B, Werner B, Wroblewska-Kaluzewska M. Assessment of cardiac arrhythmia in children after percutaneous closure of secundum atrial septal defect with Amplatzer septal occluder. Folia Cardiol 2006; 13: 427-31.

16. Kort HW, Balzer D T, Jonson MC. Resolution of right heart enlargement after closure of secundum atrial septal defect with transcatheter technique. J Am Coll Cardiol 2001; 38: 1528-32.

17. Vogel M, Berger F, Dähnert I, Ewert P, Lange PE. Treatment of atrial septal defects in symptomatic children aged less than 2 years of age using the Amplatzer septal occluder. Cardiol Young 2000; 10: 534-7.

18. Eerola A, Pihkala J I, Boldt T, Mattila I, Poutanen T, Jokinen E. Hemodynamic improvement is faster after percutaneous ASD closure than after surgery. Catheter Cardiovasc Interv 2007; 69: 432-41.

19. Acar P, Saliba Z, Bonhoeffer P, Sidi D, Kachaner J. Assessment of the geometric profile of the Amplatzer and Cardioseal septal occluders by three dimensional echocardiography. Heart 2001; 85: 451-3. 